\title{
The Science of Deception Detection: A Literature and Policy Review on Police Ability to Detect Lies
}

Journal of Criminal Justice and Law: Official Journal of the Law and Public Policy Section of the Academy of Criminal Justice Sciences Volume 3, Issue 2, pp. 40-58 (2020)

\section{Jillian R. Yarbrough '}

\begin{abstract}
Humans have a strong "truth" default, meaning that when processing incoming information, they will passively believe statements made by others. However, idle acceptance can put people at risk for deception (Levine, 2019). Research shows that $60 \%$ of people lie during a typical 10-minute conversation (Bradberry, 2017). Considering the pervasiveness of lying, it is easy to recognize deception as a challenge for individuals involved in law enforcement because they are expected to distinguish between truth and lies daily. If deception detection is an essential component of law enforcement, are techniques available that law enforcement can apply during interrogations to improve the chances of effective deception detection? This paper will examine deception detection in the law enforcement interrogation process. Specifically, it will provide an overview of the problem and five strategies law enforcement might use to detect deception, discusses the strengths and challenges of each technique, and offers recommendations to support efficient deception detection techniques in an interrogation.
\end{abstract}

Humans have a strong "truth" default when processing incoming information, and their tendency to believe others passively puts them at risk for falling victim to deceptions (Levine, 2019). Deception occurs when one person acts is a way that causes another person to accept as truth something that is false or invalid. This is a concern because deception is a pervasive problem in human behavior (McHaney, George, \& Gupta, 2018). Not only is lying pervasive, but most people struggle to detect lies. Lie detection research has shown that observers who rely on cues alone

\footnotetext{
' West Texas A \& M University, Canyon, TX, USA.

Corresponding Author:

Jillian R. Yarbrough, West Texas A \& M University, Canyon, TX, 79016

Email: jryarbrough@wtamu.edu
}

The authors wish to express their appreciation to the blind reviewers of the original manuscript for their comments, which were helpful during preparation of the final version of the manuscript. 
correctly classify on average $54 \%$ of truths or lies (Vrij, Meissner, \& Kassin, 2015). The accuracy of passive deception detection is just a little better than chance, and active detection, which requires gathering information, fact-checking communication content, strategically prompting deception cues, encouraging honest admissions, and discouraging continued deceit (Levine, Fiske, Borgida, \& Major, 2014), is not much more effective. Even with gathering facts, research suggests that most people are still unsuccessful at distinguishing truths from lies at a level significantly greater than chance (Bradford \& Goodman-Delahunty, 2008). Clearly, detecting deception is arduous.

The importance of the ability to detect deception is amplified in forensic contexts, in which the consequences of detection have significant implications (Bradford \& Goodman-Delahunty, 2008). Consider that research indicates that police officers believe they can detect deception during interviews of suspects (Hill \& Moston, 2011), and research also indicates that police, generally, cannot determine any better than laypersons whether suspects are being honest (Kassin, 2008a). This dichotomy is of concern because officers may believe their ability to detect deception is heightened, and this perception can be a catalyst for making errors in an investigation. Just one error in an assessment of deception can lead to significant consequences for law enforcement, such as loss of time, loss of resources, and even false confessions. Recognizing that law enforcement must use interrogations to determine if a person being interviewed is a witness or a suspect and then piece together events, the need to be able to identify deception emphasizes the importance of ongoing training in deception detection. Detecting deception in the interrogation process is difficult and enhanced, as is a realistic assessment of the ability to detect deception; therefore, training in deception detection strategies and techniques can support the goal of police investigation. These strategies must be studied to be used correctly, and they must be used in conjunction with fact gathering and a transparent assessment of information if deceit is to be detected effectively.

To encourage awareness and ongoing training, this paper will examine deception detection in the interrogation process, providing specifically an overview of the problem, a discussion of five strategies law enforcement might use to detect deception, a discussion of the strengths and challenges of each of the five described techniques within the interrogation process, and finally recommendations to support efficient deception detection techniques that may be beneficial to law enforcement conducting interrogations.

\section{OVERVIEW OF THE PROBLEM}

Interrogations begin as an interview process with the intent of gathering information. As the police ask questions and the interviewee provides answers, the police are determining in their minds if the interviewee is an innocent bystander or a suspect. Although an interrogation can begin with the purpose of gathering information, if the information is incriminating, is not supported by facts, or does make sense, law enforcement may decide the individual being interrogated is guilty. If officers determine that a suspect is guilty, they may develop "tunnel vision," which obscures other possibilities, and ultimately they will seek confirmation of their ideas (Rossmo \& Pollock, 2014). Once a conclusion has been developed, people rarely pay attention to any evidence that might be contradictory (Rossmo \& Pollock, 2014). This occurrence, a confirmation bias, can cause an interrogation process to shift from seeking information to seeking a confession. When efforts shift to building a case against a suspect, ignoring or minimizing countervailing evidence and 
interpreting ambiguous evidence in a way that supports the initial conclusions, potential errors can create an environment that supports false confessions and wrongful convictions (Rossmo \& Pollock, 2014; Sullum, 2019).

Picture the following scenario: A suspect is seated in an interrogation room. Police have spent hours working to identify and bring this individual in for questioning. One police officer is in the room, with other officers watching at a distance. As the interview progresses, it becomes clear that the suspect is going to maintain the claim that he has no information about a store theft early in the week. Yet two witnesses are certain they saw the suspect not only at the store but also stealing an item. The police officer recognizes the amount of law enforcement time and energy that has been spent identifying this suspect, and the officer knows it is important that these efforts pay off. The officer askes one more time, "Were you at the store?" The suspect sighs, looks away, squints, and then looks down at his hands. The police officer thinks, "We got him," because the officer interprets the gaze aversion as a definite indication of deception. With his internal confirmation, the officer prepares to dig in and intensify the interrogation tactics.

The officer's interpretations are a significant concern because interpretations may guide the investigation. A study by Hill and Moston (2011) determined that most police officers believe they can detect deception. In a sample of 2,800 police officers, the researchers found that $88.1 \%$ of the officers believed they could detect deception during suspect interviews, and $67.9 \%$ of the officers were making their assumptions on the basis of observations of nonverbal behavior. These findings are common. Stromwall and Granhag (2001) also found that most police officers believe there is a strong relationship between deceptive behavior and gaze aversion and body movements. However, despite special training on how to conduct interviews, police cannot tell any better than laypersons whether a suspect is lying or telling the truth (Kassin, 2008a). In fact, some literature has concluded that the accuracy of police deception detection may be below average. Garrido, Masip, \& Herrero. (2004) reported that police officers' overall accuracy with deception detection was approximately $47 \%$, whereas law observers obtained an overall accuracy rate of $59 \%$.

Some police officers' ability to detect deception may be below average for several reasons. First, a liar's testimony can be more persuasive than a truthteller's (Talbot, 2007; Gordon, 2018). Second, different individuals may act differently when they are lying, and attempts to categorize these differences are not reliable (DePaulo, 2013). Third, confirmation bias, group think, publicity, and incentives to identify a perpetrator quickly may lead police to target innocent people for interrogation on the basis of erroneous judgments, and innocent people are sometimes induced to confess as a function of police interrogation tactics (Rossmo \& Pollock, 2014; Kassin, n.d.).

This third issue is especially significant; not only is the idea that officers may compel an innocent person to confess to a crime on the basis of erroneous judgments scary, but the consequences of these actions can be significant, overwhelming, and possibly insurmountable. Leo (1996) and Cassell and Hayman (1996) found that suspects who provided incriminating information in their interrogations were more likely to be charged, plead guilty, and be found guilty. Leo and Ofshe (1998) conducted a study of 60 false confessions and found that $73 \%$ of those false confessors whose cases went to trial were convicted. Drizin and Leo (2004) conducted a similar study, and the conviction rate increased from $73 \%$ to $81 \%$ among 125 false confessions.

Awareness regarding false confessions has been growing for nearly 100 years. In 1936, Brown v. Mississippi was the first case in which the U.S. Supreme Court excluded a confession from a state court prosecution because the three suspects had been tortured for days during their 
Journal of Criminal Justice and Law

interrogations (Gross \& Possley, 2016). Reforms to the American courts and the criminal justice system and the development of the Miranda warning reduced torture in the interrogation process and supported a shift toward interrogation methods like isolation and exhaustion (Gross \& Possley, 2016). Certainly, these are improvements; however, police-induced false confessions remain the leading cause of wrongful convictions (Facts and Figures, 2009).

\section{INTERROGATION ERRORS}

Police interrogators make three kinds of errors-misclassification, coercion, and contamination - that can lead to false confessions (Leo \& Drizin, 2010).

- Misclassification error: Police mistakenly believe an innocent person is guilty.

- Coercion error: During the interrogation process, the police use techniques that break down a suspect's resistance to guilt. These can include lying about the existence of evidence and telling the suspect that punishment will be harsher if he or she does not confess.

- Contamination error: Police shape the suspect's statements and add details to the confession to make the statements more persuasive.

On the basis of these errors, police may experience confirmation bias, and innocent people can be induced to confess through the police interrogation process. Suspects may make a statement of guilt to escape from a stressful interrogation process, avoid punishment, or gain a promised or implied reward (Kassin, 2008b).

Because we cannot accurately quantify the number of false confessions, the true number is unknown, but we can identify that with advancing technologies, more people are being exonerated of crimes for which they received convictions but did not commit. The National Registry of Exonerations (NRE) found that between 1989 and 2017, a total of 2,161 exonerations occurred in the United States (The Innocence Staff, 2018). This information indicates that incorrect assessments of a witness's credibility and/or truthfulness can lead to miscarriages of justice (Wagenaar, Van Koppen, \& Crombag, 1993; Wells et al., 2000).

Incorrect assessments of a witness's credibility and truthfulness can lead police to make errors in the interrogation process. Two of these errors will be discussed. First, some police may inaccurately believe they are better at deception detection than other people. Second, some police may fail to conduct proper interrogations.

\section{Police Believe They Are Better at Deception Detection Than Other People}

The literature shows that police believe they are better at deception detection than other people (Elaad, 2003). It does seem reasonable that people with more experience detecting deception, like seasoned law enforcement, should be better than others, maybe even experts, in deception detection. However, research indicates that experts in lie detection do not exist; in fact, no reliable differences in deception detection accuracy are found when "experts" are compared with novices in lie detection.

Henderson and Hess (1982) (as quoted in DePaulo and Pfeiffer, 1986) and DePaulo, Ruben, \& Milner (1987) found that experienced detectives were no more accurate than college students at 
detecting deception on the basis of verbal and nonverbal cues. Masip and Herrero (2015) conducted a study to determine the validity of behavioral deception questions. In this study, police officers and community members were compared, and both groups indicated that they believed behavioral cues were reliable indicators of deception. Relative to the community members, the officers provided more cues and referred more often to verbal contradictions and active detection strategies when asked about their beliefs. Throughout the study, all the participants held to their beliefs that they could detect deception cues. Masip and Herrero (2015) concluded that it is important for people to shift from seeking cues to active detection, in which the interviewer is taking contextual information into account.

Elaad (2003) also studied police officers and found that they tend to overestimate their capacity to detect lying. In this study, 60 police officers engaged in a lie detection task and were asked to assess their accuracy in detecting lies. The officers performed below the chance level, yet they evaluated their accuracy as high. Interestingly, when the officers received confirmation of the effectiveness of their deception detection, their notion of their abilities increased, whereas after negative feedback, the officers rated their lie detection abilities lower. On a practical level, the tendency of police interrogators to overestimate their ability to detect deception can change suspicion into certainty and increase the risk for a false confession.

Several studies have asked police to view videos of people and detect deception. Kohnken (1987) asked police officers to watch videotaped statements of witnesses-some truthful, some lies. The study showed the mean accuracy of the officers to be .47 , with .5 being chance, .36 false statements, and .63 truthful statements. Vrij (1992) examined experienced detectives' ability to detect deception within the context of the police interview. In this study, officers saw video tapes showing behavioral differences between liars and truth tellers. The detectives had to determine whether the participants were telling the truth, and their overall accuracy was .49. Finally, Garrido et al. (1997) conducted a study in which police recruits and undergraduate college students were asked to judge whether a videotaped female subject was telling truths or lies. The police officers and the students were equally accurate at detecting lies, but the officers were less accurate at identifying truthful statements, displaying a lie bias.

The study of Garrido et al. (1997) was not the first to compare police officers' ability to detect lies with that of undergraduate students. DePaulo and Pfeiffer (1986) asked experienced officers, new recruits, and undergraduates to judge several types of audio tapes with the intent of determining truths and lies. The raters indicated whether they thought each response was truthful or deceptive, in addition to their degree of confidence in each judgment. The officers were no more accurate than the students in their judgments about truths and lies. Additionally, the accuracy rates of the experienced and novice officers did not differ significantly; they were $54.3 \%$ for the students, $52.9 \%$ for the new recruits, and $52.3 \%$ for the experienced officers. Both the experienced and the inexperienced police officers were more confident than the students about their judgments. The experienced officers were more confident about their judgments regarding the lies than about their judgments regarding the truths, whereas the students displayed the reverse pattern.

Ekman and O'Sullivan (1991) studied seven groups of people: members of the U.S. Secret Service, federal polygraphers, police officers, judges, psychiatrists, lay people, and students. All the groups viewed 10 videotaped samples, each showing a girl answering questions about how she felt regarding a film she was watching. Participants had to say whether each of the samples was 
honest or deceptive. The Secret Service group was more accurate than any of the other six groups. The researchers found a relationship between experience and accuracy only for the Secret Service; none of the groups were effective lie detectors, nor were the officers better lie detectors than nonofficers.

In this brief review of the literature, police officers report confidence in their ability to detect deception, yet in many research studies, the officers score average to below average. If an officer who is conducting an interrogation believes he or she can tell lies from truths, the chances that a suspect will be erroneously identified and convicted of a crime may be increased.

\section{Interrogations Must Follow Proper Procedures}

While police display normal human limitations in terms of deception detection, they at the same time carry a significant responsibility in terms of conducting fair and legal interrogations. Just as an erroneous assumption on the part of an officer can lead to errors in conviction, so can inaccuracies in the interrogation process. Errors in the interrogation process can create a scenario in which police are more likely to rely on their assumptions than on details, information, and policies. Most notably, interrogation errors may violate the Fifth and Sixth Amendments of the U.S. Constitution.

The Fifth Amendment protections include the right to remain silent and avoid selfincrimination. The Fifth Amendment involves Miranda rights and concerns the following:

- Individuals have the right to remain silent.

- Anything they say can and will be used against them in a court of law.

- Individuals have the right to speak to an attorney.

- If they cannot afford an attorney, one will be appointed for them.

Before an interrogation, suspects must be informed of these rights, and they must be allowed access to a lawyer when one is requested.

The Sixth Amendment protections stop a police interrogation and give people the right to a jury trial, a speedy trial, and other court procedural rules. They also prevent police from questioning suspects without an attorney present once charges have been filed. Any statements made to police without an attorney present after charges have been filed should be suppressed.

Although police usually follow constitutional law in the interrogation process, they do not always follow psychological recommendations. Concerns regarding police interrogations and false confessions have brought together scholars and practitioners in social psychology, cognitive psychology, developmental psychology, and clinical-forensic psychology (Lassiter \& Meissner, 2010). To minimize concerns about false confessions, it is important that psychological recommendations regarding inducements and impediments within the interrogation process be examined and implemented by law enforcement (Lassiter \& Meissner, 2010).

\section{DECEPTION DETECTION TECHNIQUES}

Many factors contribute to false confessions, such as a lengthy interrogation, the manufacturing of evidence, the minimization of information, an officer's belief in his or her ability to detect deception, and the use of torture. Although all are important, an officer's belief that a 
suspect is guilty creates a scenario in which the interrogation is conducted with the goal of obtaining a confession. This is a concern because the literature shows that an officer's ability to detect deception is generally consistent with that of chance. Some specific deception detection techniques that officers may use to enhance their capacity to detect deception include the following: monitoring of true/false intentions, examination of cues, group detection methods, advanced individual skills like detection wizardry, and finally polygraphy/functional magnetic resonance imaging ( $f M R I)$. Each of these detection methods will be discussed, with a definition of the technique and a consideration of its potential strengths and challenges in regard to application in interrogations.

\section{True/False Intentions}

One strategy that detectives may use to determine deception in an interrogation process is an analysis of true/false intentions. This concept suggests that the mental representations and communication patterns of true intentions will differ from those of false intentions. For example, psychologically distant tasks, unlikely tasks, are more abstractly represented than psychologically proximal tasks, likely tasks. According to this idea, in an interrogation, false intentions should be more abstractly represented than true intentions (Calderon, 2019). Kleinberg, Nahari, Arntz, \& Verschuere (2017) conducted a study to examine deception detection, comparing statements about someone's past events and someone's intentions for the future. Their research was based on the verbal deception detection paradigm, which states that truthful statements differ from false declarations in quality and content because the processes through which the statements are produced are different (Fornaciari \& Poesio, 2013). For example, truthful statements may contain more references to persons, events, and locations than deceptive statements. On the basis of this idea, the researchers expected that truth tellers' accounts would contain more detailed information than those of liars. Two hundred twenty-two participants were asked to lie or tell the truth about their upcoming travel plans, either providing as much information as possible or being as specific as possible. Data were collected via a custom-made Web app that performed an automated verbal content analysis of the participants' written answers with Linguistic Inquiry and Word Count software. The computer-automated verbal content analysis attempted to differentiate between participants who provided truthful statements and those who gave deceptive statements about an upcoming flight. Interestingly, differences in verbal content were not revealed between the participants' truthful or deceptive statements about their upcoming flight - that is, true/false intentions were not detectable.

In regard to interrogation, the strengths of this study include examining deception from two perspectives-one recognizing that past memories can help someone devise deceptive statements because real memories can offer context for the lies, and the other recognizing that technology may eventually be able to help analyze and identify deception. The study presents challenges for deception detection in interrogations, concluding that currently, Linguistic Inquiry and Word Count software technology-automated analysis-does not have the capability to detect lies.

In the study of Calderon, Mac Giolla, Ask, and Granhag (2018) on deception detection, the researchers examined how people mentally represent and depict true and false statements about their future. For this study, true intentions were defined as alleged future actions that were genuinely intended to be carried out, and false intentions were defined as alleged future actions that were not intended to be carried out. The researchers asked one set of participants to draw 
mental images accompanying either true or false intentions, and then a second set of participants was asked to rate the drawings for level of abstraction. On the basis of construal level theory (CTL), which suggests that one's psychological distance from an event will influence how abstractly or concretely the event is mentally construed, the researchers expected that the drawings with false intentions would be rated as more abstract. One hundred seventeen participants rated the previously prepared drawings on a Likert scale of 1 to 7 . The results showed a high level of agreement among the participants as to which drawings were abstract and which drawings were concrete, with the false intention drawings receiving more ratings of abstraction than the true intention drawings.

A consideration of this study as it relates to the interrogation process reveals some strengths and some weaknesses. A strength is that it might be helpful for officers to be aware that lies tend to include relatively abstract descriptions and that abstraction may suggest deceit. The study used drawings to communicate information. Another strength might be to have officers ask a suspect to draw what was seen or experienced, then evaluate the suspect's drawing for an abstract or concrete appearance. Calderon et al. (2018) also introduced a potential challenge for officers attempting to detect deception in an interrogation. The researchers added a caveat to their study, stating, "In real-life situations, where people's motivation to be believed is naturally stronger than in a laboratory setting, liars may try harder to provide concrete drawings as a strategy to appear credible" (Calderon et al., 2018, p. 521). In other words, concrete drawings may indicate a truth teller, or they may indicate a strategic liar who has added detail to be believed.

\section{Examination of Cues}

When relying on cues, one can examine and identify clusters of verbal and nonverbal displays in the interrogation process and compare these displays against a baseline of established verbal and nonverbal cues offered at a time when people have no reason to lie (Schafer, 2017). Deviations from the baseline may indicate deception. Research by Calderon et al. (2018) not only looked at true/false intentions but also identified that abstraction with false or true intentions may be a cue to deception. Looking for indications or cues in words or behaviors is a common deception detection technique. A great deal of research has been conducted on examining cues as signals of active deception.

Levine et al. (2014) examined the effectiveness of analyzing cues to detect deception. The researchers found that active deception detection requires three things: gathering information to fact-check the communication content, strategically prompting deception cues, and encouraging honest admissions and discouraging continued deceit. With active deception detection many dynamic factors are involved, and not all active deception detection techniques are equally effective. As an example, judgments made after direct interaction with a potential liar can produce outcomes similar to those of passive observation absent of any interaction $(52.8 \%$ vs. $52.6 \%$; Bond \& DePaulo, 2006). The presence or absence of probing questions is unrelated to accuracy (Levine \& McCornack, 2001), and no correlation is found between interview duration and detection accuracy (Levine, Blair, \& Clare, 2014; Levine, Shaw, \& Shulman, 2010). In other words, merely interacting with or questioning a suspect will not provide more conclusive information for understanding cues than simple passive observation. However, an active interrogation approach focusing on communication, content, and persuasion may yield better results when the suspect's answers are understood in the context of gathered facts. 
This article offers several strengths for officers working to detect deception in an interrogation situation. First, it emphasizes the importance of active deception detection, which includes paying attention to information and gathering facts, both of which should be used in conjunction with the observation of cues to understand a suspect. The article also presents some challenges to officers in the interrogation process, as it emphasizes that not all active deception detection techniques will be effective. In other words, no fail-proof method of deception detection exists.

An article by Dunbar, Jensen, Harvell-Bowman, Kelley, and Burgoon (2017) also examines the effectiveness of cues in deception detection. This research evaluated an alternative type of deception detection training called rapid judgment (RJ) coding, first proposed by Vrij, Evans, Akehurst, and Mann (2004). With RJ coding, lie detection judges are trained to focus on indirect accurate indicators of deceit, such as the amount of detail given and certain exhibited verbal and nonverbal differences, rather than to make direct credibility judgements. To test the effectiveness of RJ coding for lie detection, the researchers first prepared training materials on seven specific RJ codes and then offered coders training based on the descriptions found in Vrij et al. (2004). The RJ approach to coding suggests that when people are asked to pay attention to verbal and nonverbal cues, rather than to detect deceit, they are more accurate in their judgments (DePaulo \& Morris, 2004).

The research on RJ coding does introduce strengths and challenges into the process of deception detection in interrogations. One strength is the idea that detectives and officers can be trained to pay attention to verbal and nonverbal cues to improve the accuracy of their judgments. However, the authors also communicate that using RJ effectively is much more challenging than engaging in a simple conversation or observing actions (Giordano, George, Marett, \& Keane, 2011).

\section{Group Detection Methods}

Research certainly indicates that for individuals, detecting deception is very challenging. With this idea in mind, experts have examined if groups are more effective than individuals at detecting deception. Specifically, group deception detection focuses on the design and use of groups and group processes to aid deception detection (Deokar \& Madhusudan, 2005). McHaney et al. (2018) used three independent groups to examine the effectiveness of group deception detection; participants were classified as individuals, members of an ad hoc group, or members of an established group. The participants in each group watched a series of eight video clips taken from recorded face-to-face interviews and then answered questions about true or false information entered on a scholarship application. The research participants were instructed to indicate their assessment of the level of deception used by the video subjects on a 7-point Likert scale. The individual participants made accurate choices $53 \%$ of the time, members of the ad hoc group specifically created for the study were accurate $53 \%$ of the time, and members of the established group were accurate $67 \%$ of the time. The researchers drew two conclusions: first, preexisting groups may be more accurate than individuals in the detection of deception; second, group effectiveness correlates with the strength of the relational links, and stronger links are associated with more effective group information exchange (Warkentin, Sayeed, \& Hightower, 1997).

This research offers information that can help officers detect deception and highlights some challenges that may arise in the deception detection process. First, it indicates that deception detection may be improved when the members of an established group work collectively to 
uncover deception. The article also highlights that deception detection through a group process may be challenged if the group is dysfunctional.

In a study by Zhou, Zhang, and Sung (2013), the researchers proposed that group factors, including diversity and familiarity, will influence the effectiveness of deception detection. On the basis of data collected from real-world online communities, the study concluded that familiarity of the members of a group with fellow members' behaviors positively affects the ability of the group to detect deception. Further, gender diversity has a negative effect on the ability of a group to detect deception.

The study offers valuable insights that may strengthen deception detection in the interrogation process and highlights some potential challenges for effective detection. According to the research, creating a group whose members are familiar with fellow group members' behaviors can have a positive effect on deception detection. The study also emphasizes that deception detection may be challenging for groups with gender diversity, possibly because gender diversity creates a less homogeneous group, which in turn results in a lower degree of behavioral familiarity.

\section{Detection Wizards}

Researchers have considered whether any tools or strategies can facilitate the identification of deception. Researchers have also examined whether some people are naturally more effective at identifying deceit. The idea of detection wizards was introduced by O'Sullivan and Ekman in 2004, and these two researchers believed that a few special individuals could achieve aboveaverage accuracy in detection deception. They suggested not only that detection wizards exist, but that they are particularly effective at detecting deception because of their high degree of emotional intelligence. This allows them to identify nonverbal cues of deception more accurately than others (O'Sullivan \& Ekman, 2004). In the interrogation process, the inclusion of wizards, individuals who are exceptionally good at detecting deception, could be beneficial for officers seeking to discern deceit.

Multiple researchers have considered and reviewed the work of O'Sullivan and Elkman (2004). Two such studies will be discussed. First, Roulin and Ternes (2019) examined the concept of deception detection wizards and argued that they likely are nonexistent. In their study, the authors challenged the idea of detection wizards by measuring deception detection in two different approaches (in-person and video-based) and two different contexts (social interaction and job interview). Results showed that individuals with a high degree of emotional intelligence do rely more than others on nonverbal information, and that the use of nonverbal cues is not related to deception detection. Combined with the findings of earlier studies raising methodological and statistical issues associated with the wizard hypothesis (Bond, 2008; Bond \& Uysal, 2007), the findings of this study provide additional evidence that detection wizards are likely a myth.

This research offers strengths, providing strategies for supporting deception detection, and challenges, highlighting areas that make deception detection in interrogations difficult. The strengths include an emphasis on the complications associated with detection, which can help police understand that deception detection is unlikely to be easy. This is valuable information that can encourage officers to rely on facts and reality rather than assumptions. The article also includes a challenge for effective deception detection, stating that not enough information is currently 
available to allow a determination of whether or not detection wizards exist. This conclusion may leave room for some officers to consider themselves detection wizards.

In a later study, Bond and Uysal (2007) explored the previous research of O'Sullivan and Ekman (2004). Bond and Uysal offered a statistical critique of detection wizardry claims and concluded that no convincing evidence supports the idea that lie detection wizards have ever existed. The article is helpful for deception detection because it communicates clearly that detection wizards do not exist. This information can encourage detectives to rely on data and facts in their interrogations rather than assumptions of their own deception detection skill. The article presents challenges for deception detection by emphasizing that no clear evidence supports the existence of detection wizards, and it again underscores that detecting deception is very difficult and that no deception detection experts are likely to exist.

\section{Polygraphy and fMRI}

While some researchers have examined cues, intentions, and collaboration as support for deception detection, others have considered the use of technology, like polygraphy and fMRI. A polygraph measures the activity of the peripheral nervous system, which is used to gauge truthfulness (Langleben \& Moriarty, 2013), and fMRI measures small and variable changes in the ratio of oxygenated to deoxygenated blood in the brain (Langleben, 2008). In theory, such changes may serve to indicate deception. Detectives may seek to use technology to scan physical responses and determine whether statements are true or false. Technology in the interrogation process not only influences officers but also may have an undue effect on jury decisions. Reliance on polygraphy results can cause significant problems (Han, 2016).

This literature review emphasizes that polygraphy is both a strength and a challenge in deception detection. The polygraph test is of different value to different people in different states and in different capacities. It is helpful for law enforcement to understand that whereas a polygraph test may offer strength as an additional tool that provides further information, it simultaneously creates challenges for deception detection because it is not viewed as reliable by all experts and is not admissible in court. If officers use a polygraph in the interrogation process, might the tool not simply encourage them to make decisions based on inadmissible information rather than on facts and details?

In another polygraph study, Meijer and Verschuere (2017) considered the use of brain imaging, $\mathrm{fMRI}$, for the detection of deception. This method has attracted attention because it may overcome some of the shortcomings of polygraphy. However, the researchers identify that no unique physiological response and no particular brain region are associated with deception. Decisions are determined by logical inferences, and deception is inferred from cognitive control. Critics voice concerns about the test and argue that it can be used in only a small number of cases. The article provides valuable information, explaining the strengths and challenges of the application of $\mathrm{fMRI}$ in deception detection. As a strength, police can feel confident that more and more forms of technology are being examined for their potential value in identifying deceit. In terms of challenges, the article concludes that at this time, fMRI, will not help officers detect deception. 
Journal of Criminal Justice and Law

Table 1: Overview of the Relevant Literature on Deception Detection

\begin{tabular}{|c|c|c|}
\hline & Strengths & Weaknesses \\
\hline $\begin{array}{l}\text { True/False } \\
\text { Intentions }\end{array}$ & $\begin{array}{l}\text { 1. Past memories can help someone } \\
\text { offer deceptive statements as real } \\
\text { memories and can offer context for } \\
\text { lies. } \\
\text { 2. Lies may be more abstract and } \\
\text { abstraction may be a potential cue of } \\
\text { deceit. }\end{array}$ & $\begin{array}{l}\text { 1. Linguistic Inquiry and Word Count } \\
\text { software technology does not appear to } \\
\text { facilitate the identification of deception. } \\
\text { 2. If someone, such as a sociopath, is } \\
\text { comfortable lying, that person may be able } \\
\text { to offer detailed, descriptive lies. }\end{array}$ \\
\hline Cues & $\begin{array}{l}\text { 1. Active deception detection is } \\
\text { important and includes paying } \\
\text { attention to information and gathering } \\
\text { facts, both of which should be used in } \\
\text { conjunction with cues to understand a } \\
\text { suspect. } \\
\text { 2. Officers can be trained to use rapid } \\
\text { judgments (RJs) and to pay attention } \\
\text { to verbal and nonverbal cues. }\end{array}$ & $\begin{array}{l}\text { 1. The article presents some challenges to } \\
\text { officers, emphasizing that not all active } \\
\text { deception detection will be effective and } \\
\text { that there is no fail-proof method of } \\
\text { deception detection. } \\
2 \text {. RJs do not discriminate between truth } \\
\text { and deception, and the research reinforces } \\
\text { that deception detection is challenging, } \\
\text { requiring the monitoring of vocal and } \\
\text { nonverbal cues as well as an examination } \\
\text { of the verbal content of a statement for } \\
\text { logical inconsistencies. }\end{array}$ \\
\hline Group Methods & $\begin{array}{l}\text { 1. Deception detection may be } \\
\text { improved when an established group } \\
\text { that is cohesive and satisfied works } \\
\text { collectively to uncover deception. } \\
\text { 2. Creating a group that is familiar } \\
\text { with group members' behaviors can } \\
\text { have a positive effect on deception } \\
\text { detection. }\end{array}$ & $\begin{array}{l}\text { 1. Deception detection is challenged by } \\
\text { group dysfunction. } \\
\text { 2. Gender diversity can have a negative } \\
\text { effect on deception detection. }\end{array}$ \\
\hline $\begin{array}{l}\text { Detection } \\
\text { Wizards }\end{array}$ & $\begin{array}{l}\text { 1. Most people cannot effectively } \\
\text { detect lies. } \\
\text { 2. Deception detection wizards do not } \\
\text { exist. }\end{array}$ & $\begin{array}{l}\text { 1. Current information is insufficient to be } \\
\text { conclusive about whether or not detection } \\
\text { wizards exist. } \\
\text { 2. Challenges exist not only in detecting } \\
\text { deception by suspects but also in detecting } \\
\text { deception by forensic professionals. }\end{array}$ \\
\hline Polygraphy & $\begin{array}{l}\text { 1. The polygraph is valued by some as } \\
\text { offering insight into deception. } \\
\text { 2. Functional magnetic resonance } \\
\text { imaging (fMRI) is a new tool with the } \\
\text { potential to examine internal } \\
\text { individual responses so that decisions } \\
\text { are not based on assumptions. }\end{array}$ & $\begin{array}{l}\text { 1. Polygraphs are not admissible in court, } \\
\text { and they are discounted by many people. } \\
\text { 2. Researchers conclude that fMRI has } \\
\text { done little to overcome the problems } \\
\text { associated with deception. }\end{array}$ \\
\hline
\end{tabular}

\section{SUMMARY OF DECEPTION DETECTION TECHNIQUES IN THE LITERATURE}

On the basis of the literature review provided in this paper, a few conclusions can be drawn. First, deception detection is difficult, and all the literature confirms this idea. Second, assumptions 
about deception by others are generally not reliable, and factors like experience and the observation of body language do not necessarily enhance one's ability to detect deception. Third, deception detection technology, such as polygraphy and even fMRI, is not reliable and not admissible in court. Finally, the literature does support that active, engaged deception detection that involves gathering facts, listening, asking questions, and collaborating with other engaged professionals may make it possible to identify gaps in information about suspects. The literature review is summarized in Table 1 below.

\section{RECOMMENDATIONS}

Challenges with deception detection are particularly concerning for police and detectives, who must conduct interrogations to determine if a suspect should be detained, questioned further, or let go. Some officers may believe they are effective at detecting deception because of enhanced training, experience with deception detection, and awareness of behavioral cues. However, throughout the literature, research shows that police officers are about as effective as chance at identifying deception. Most concerning is that under some circumstances, police were less effective than chance. An officer's ability to be effective in the interrogation process is critical. The facts are established during the interview, and therefore the need to discern whether someone is lying or not is truly compelling. Clearly, police errors in detection deception result in long-term, significant consequence for individuals, communities, law enforcement, the legal system, and justice within the United States. With this in mind, two recommendations to support effective and efficient interrogation procedures will be offered: increased training for law enforcement specifically addressing deception detection and mandatory recording of the entire interrogation processes.

\section{Increased Forensic Psychologist-Based Training}

It is important for police to be aware of the ongoing psychological research regarding interrogation procedures and police effectiveness in deception detection. It is equally important that police be given training, tools, and methods to use in conjunction with the interrogation process to maximize their accuracy and efficiency in detecting deceit. The author proposes that police continue to receive training about deception. In addition to training, police should receive ongoing access to research that communicates the likelihood of accurate deception detection, the consequences of false confessions, and strategies for collecting information and aligning the responses of suspects in interrogations with collected information to find gaps requiring further exploration.

One way to support improved training and learning about proper interrogation practices is to increase forensic psychologist involvement in the interrogation process. Forensic psychologists may provide training to police interrogators about deception detection, false confessions, and confirmation bias. They may also give expert opinion to law enforcement after examining videotaped interrogations. Finally, in support of effective legal procedures, forensic psychologists can provide information helping law enforcement, judges, and jurors understand the coercive nature of the interrogation process and its effect on suspects' behavior (Alarez-Toro \& LopezMorales, 2018). 
Journal of Criminal Justice and Law

\section{Policy Reform: Mandatory Videotaping of the Entire Interrogation Process}

In addition to ongoing training regarding deception detection, interrogation-related policies can benefit from other reform. One recommended reform is to mandate videotaping of the entire interrogation process. Dr. Saul Kassin, Distinguished Professor at the John Jay College of Criminal Justice, has pioneered the scientific study of police interrogations and false confessions. He has identified one critical reform: "Without equivocation, our most essential recommendation is to lift the veil of secrecy from the interrogation process in favor of the principle of transparency" (Kassin, Drizin, Grisso, Gudjonsson, Leo, \& Redlich, 2010, p. 25). Dr. Kassin recommends that police be required to videotape all interrogations in their entirety, not just the final confession. Mandatory recordings may "deter police from using egregious interrogation tactics, inhibit frivolous defense claims of coercion, and make judges and juries more accurate fact finders of confession evidence" (American Psychological Association, 2019). The policy to mandate recording is supported by the American Bar Association (2004), the American Psychological Association (2014), Buckley \& Jayne (2005), and The Justice Project (2007). In addition, police from hundreds of departments that record entire custodial interrogations consistently report benefits and fully embrace the practice (Sullivan, 2004). Identified benefits of recording entire interrogations include allowing detectives to focus on the suspect rather than on note taking, creating a record for later review, lessening the need for detectives to defend their interrogation practices in court, and enhancing public trust (Sullivan, Vail, \& Anderson, 2008). According to The Innocents Staff (2020), about half of the states, in addition to the District of Columbia, currently require recording during a custodial interrogation: Alaska, Colorado, Connecticut, Illinois, Indiana, Kansas, Maine, Maryland, Massachusetts, Michigan, Minnesota, Missouri, Montana, Nebraska, Nevada, New Jersey, New Mexico, New York, North Carolina, Oklahoma, Oregon, Texas, Utah, Vermont, and Wisconsin,. It is recommended that all states consider recording interrogation processes in their entirety.

\section{CONCLUSIONS}

Psychological theory and research show that harsh interrogation methods are ineffective; they increase resistance by the subject rather than facilitate cooperation, reduce the retrieval of information from memory, and make lie detection difficult (Vrij et al., 2017). It is interesting to consider the significant contrast between the findings of psychological research and the assumptions of officers. Throughout the literature, researchers emphasize that there is no sure way to detect deception, and the literature also supports the idea that law enforcement professionals believe they are effective at detecting lies. The contrast is significant because of the authority and responsibility that law enforcement officers carry every day.

Aware of this contrast, numerous researchers have tested deception detection techniques that might enhance an officer's ability to identify lies, such as true/false intentions, examination of cues, group work for detection analysis, use of detection wizards, and polygraphy/fMRI. Throughout the studies, the researchers find some strengths, information that will enhance effective deception detection, and uncover some challenges, issues that make detection deception difficult. Regardless of the deception detection method, the researchers emphasize that no human being and no current technology can detect deception $100 \%$ of the time. At best, during interrogations, detectives can gather information, ask questions, seek corroboration, use experts, and seek to understand the suspect. Police should avoid trying to induce confessions or base 
conclusions on assumptions. The consequences of even one error in police judgment regarding innocence or guilt can be significant, and these consequences create a negative ripple effect that is amplified at each level, beginning with the individual suspect and then reaching communities, cities, states, and ultimately the entire judicial system.

With such responsibility, law enforcement officers should be offered substantial support, current and advanced training, a plethora of tools for gathering and assessing information, ongoing access to forensic psychologists, and policies that support effective interrogation procedures. With support, training, resources, and policy reform, observations and communications in the interrogation process can become a part of the suspect's story rather than the entire picture, ultimately allowing officers to rely on the big picture and gaps in information rather than on assumptions. Although no one can become a deception detection expert, we can become aware of confirmation bias and guard against forming a conclusion about an issue without further exploration of and attention to any and all evidence that might be contradictory.

\section{Declaration of Conflicting Interests}

The author declares no potential conflicts of interest with respect to the research, authorship, and/or publication of this article.

Funding

The author received no financial support with respect to the research, authorship, and/or publication of this article.

\section{Sources Cited}

Alarez-Toro, A., \& Lopez-Morales, C. (2018). Revisiting the false confession problem. The Journal of the American Academy of Psychiatry and the Law, 46(1), 34-44.

American Bar Association. (2004). Resolution 8A-Videotaping custodial interrogations. Approved February 9, 2004.

American Psychological Association. (2019). Does video recording interrogations inhibit crime suspects? Answers from a fully randomized field experiment.

American Psychological Association. (2014). Resolution on interrogations of criminal suspects.

Bond, C., \& DePaulo, B. (2006). Accuracy of deception judgements. Personality and Social Psychology Review, 10(3), 214-234.

Bond, C., \& Uysal, A. (2007). On lie detection "wizards." Law and Human Behavior, 31(1),109-115. Bond, G. (2008). Deception detection expertise. Law and Human Behavior, 32(4), 339-351. Bradberry, T. (2017). Sixty percent of your colleagues are lying to you. Huffpost.

Bradford, D., \& Goodman-Delahunty, J. (2008). Detecting deception in police investigations: Implications for false confessions. Psychiatry Psychology and Law, 15(1), 105-118.

Buckley, D. M., \& Jayne, B. C. (2005). Electronic recording of interrogations. Eagle River, WI: Hahn Printing.

Calderon, S. (2019). True and false intentions: A mental representation approach (Doctoral Dissertation in Psychology, Department of Psychology, University of Gothenburg, Gothenburg, Sweden). 
Journal of Criminal Justice and Law Official Journal of the Law and Public Policy Section of the Academy of Criminal Justice Sciences

Calderon, S., Mac Giolla, E., Ask, K., \& Granhag, P. (2018). Drawing what lies ahead: False intentions are more abstractly depicted than true intentions. Applied Cognitive Psychology, 32(4), 518522.

Cassell, P. G., \& Hayman, B. S. (1996). Police interrogation in the 1990s: An empirical study of the effects of Miranda. UCLA Law Review, 43, 839-931.

Deokar, A., \& Madhusudan, T. (2005). Developing group decision support systems for deception detection. IEEE Computer Society Digital Library, 1, 24c.

DePaulo, B. (2013). Why are we so bad at detecting lies? Psychology Today.

DePaulo, B. M., \& Morris, W. L. (2004). Discerning lies from truths: Behavioral cues to deception and in the indirect pathway of intuition. In P. A. Granhag \& L. A. Stromwall (Eds.), The detection of deception in forensic contexts (pp. 14-40). New York, NY: Cambridge University Press.

DePaulo, B. M., \& Pfeifer, R. L. (1986). On-the-job experience and skill at detecting deception. Journal of Applied Social Psychology, 16, 249-267.

DePaulo, B., Ruben, M., \& Milner, B. (1987). Stages of involvement with alcohol and heroin: Analysis of 2.e effects of marketing on action in advances. In M. Wallendorf \& P. Anderson (Eds.), Advances in Consumer Research, 14. Provo, UT: Association for Consumer Research, 521-525.

Drizin, S., \& Leo, R. (2004). The problem of false confessions in the post-DNA world. North Carolina Law Review, 82, 891-1007.

Dunbar, N., Jensen, M., Harvell-Bowman, L., Kelley, K., \& Burgoon, J. (2017). The viability of using rapid judgments as a method of deception detection. Communication Methods and Measures, 11(2), 121-136.

Ekman, P., \& O'Sullivan, M. (1991). Who can catch a liar? American Psychologist, 46, 913-920.

Elaad, E. (2003). Effects of feedback on the overestimated capacity to detect lies and the underestimated ability to tell lies. Applied Cognitive Psychology.

Facts and Figures. (2009). False Confessions.org.

Fornaciari, T., \& Poesio, M. (2013). Automatic deception detection in Italian court cases. Artificial Intelligence and Law, 21(3), 303-340.

Garrido, E., Masip, J., \& Herrero, C. (2004). Police officers' credibility judgments: Accuracy and estimated ability. International Journal of Psychology, 39, 254-275.

Garrido, E., Masip, J., Herror, C., Tabernero, C., \& Vega, M. T. (1997). Policemen's ability to discern truth from deception of testimony. Unpublished manuscript. Cited in Garrido, E., \& Masip, J. (December, 1998). How good are police officers at spotting lies? Forensic Update, 58.

Giordano, G., George, J.F., Marett, K., \& Keane, B. (2011). Reviewers and the detection of deceptive information in recorded interviews. Journal of Applied Social Psychology, 41(2), 252-269.

Gordon, M. (2018). Lying in politics: Fake news, alternative facts, and the challenges for deliberative civics education. Educational Theory, 68(1), 49-64.

Gross, S., \& Possley, M. (2016). So why do so many suspects confess to crimes they didn't commit? The National Registry of Exonerations.

Han, Y. (2016). Deceptional detection techniques using polygraph in trials: Current status and social scientific evidence. Contemporary Readings in Law and Social Justice, 8(2), 115

Hill, J. A., \& Moston, S. (2011). Police perceptions of investigative interviewing: Training needs and operational practices in Australia. British Journal of Forensic Practice, 13(2):72-83. 
Kassin, S. (2008a). Confession evidence: Commonsense myths and misconceptions. Criminal Justice and Behavior, 36(10).

Kassin, S. (2008b). False confessions: Causes, consequences and implications for reform. Association for Psychological Science, 17(4), 249-254.

Kassin, S. (n.d.). The psychology of confessions. Annual Review of Law and Social Science, 4(1), 193-217.

Kassin, S., Drizin, S., Grisso, T., Gudjonsson, G., Leo, R., \& Redlich, A. (2010). Police-induced confessions: Risk factors and recommendations. Law and Human Behavior, 34(1), 3-38.

Kleinberg, B., Nahari, G., Arntz, A., \& Verschuere, B. (2017). An investigation on the detectability of deceptive intent about flying through verbal deception detection. Collabra: Psychology, 3(1), 21.

Kohnken, G. (1987). Training police officers to detect deceptive eye witness statements: Does it work? Social Behavior, 2, 1-17.

Langleben, D. (2008). Detection of deception with fMRI: Are we there yet? Legal and Criminological Psychology, 13(1), 1-9.

Langleben, D., \& Moriarty, J. (2013). Using brain imaging for lie detection: Where science, law and policy collide. Pyschology Public Policy Law, 19(2), 222-234.

Lassiter, G. D., \& Meissner, C. A. (2010). Police interrogations and false confessions: Current research, practice, and recommendations. American Psychological Association.

Leo, R. A. (1996). Inside the interrogation room. Journal of Criminal Law and Criminology, 86, 266303.

Leo, R. A., \& Drizin, S. A. (2010). The three errors: pathways to false confession and wrongful conviction. In G. D. Lassiter \& C. Meissner (Eds.), Police interrogations and false confessions: Current research, practice, and policy recommendations (American Psychological Association, 2010); Univ. of San Francisco Law Research Paper No. 2012-04.

Leo, R., \& Ofshe, R. (1998). The consequences of false confessions: Deprivations of liberty and miscarriages of justice in the age of psychological interrogation. Journal of Criminal Law and Criminology, 88, 429-496.

Levine, T. (2019). Five reasons why I am skeptical that indirect or unconscious lie detection is superior to direct deception detection. Frontiers in Psychology.

Levine, T. R., Blair, J. P., \& Clare, D. D. (2014). Diagnostic utility: Experimental demonstrations and replications of powerful question effects in high stakes deception detection. Human Communication Research, 40, 262-289.

Levine, T., Fiske, S., Borgida, E., \& Major, B. (2014). Active deception detection. Policy Insights from the Behavioral and Brain Sciences, 1(1), 122-128.

Levine, T. R., \& McCornack, S. A. (2001). Behavioral adaption, confidence, and heuristic-based explanations of the probing effect. Human Communication Research, 27, 471-502.

Levine, T. R., Shaw, A., \& Shulman, H. (2010). Increasing deception detection accuracy with direct questions. Human Communication Research, 36, 216-231.

Masip, J., \& Herrero, C. (2015). Police detection of deception: Beliefs about behavioral cues to deception are strong even though contextual evidence is more useful. Journal of Communication, 65(1), 125-145.

McHaney, R., George, J., \& Gupta, M. (2015). An exploration of deception detection: Are groups more effective than individuals? Communication Research, 45(8), 1103-1121. 
Journal of Criminal Justice and Law Official Journal of the Law and Public Policy Section of the Academy of Criminal Justice Sciences

Meijer, E. H., \& Verschuere, B. (2017). Deception detection based on neuroimaging: Better than the polygraph? Journal of Forensic Radiology and Imaging, 8, 17-21.

O'Sullivan, M., \& Ekman, P. (2004). The wizards of deception detection. In P. A. Granhag, L. Stromwall (Eds.), The detection of deception in forensic contexts (pp. 269-286). New York, NY: Cambridge University Press.

Rossmo, K., \& Pollock, J. (2014). Confirmation bias and other systemic causes of wrongful convictions: A sentinel events perspective. Northeastern University Law Review, 11(2).

Roulin, N., \& Ternes, M. (2019). Is it time to kill the detection wizard? Emotional intelligence does not facilitate deception detection. Personality and Individual Differences, 137, 131-138.

Schafer, J. (2017). Detecting deception is possible, but not easy. Psychology Today.

Stromwall, L., \& Granhag, P. A. (2001). How to detect deception? Arresting the beliefs of police officers, prosecutors and judges. Psychology Crime and Law, 9(1), 19-36.

Sullivan, T. P. (2004). Police experiences with recording custodial interrogations. Chicago, IL:

Northwestern University School of Law, Center on Wrongful Convictions.

Sullivan, T. P., Vail, A. W., \& Anderson, H. W. (2008). The case for recording police interrogation. Litigation, 34, 1-8.

Sullum, J. (2019). New study of wrongful convictions shows problem goes beyond police, prosecutor misconduct. Chicago Sun Times.

Talbot, M. (2007). Duped. Can brain scans uncover lies? The New Yorker.

The Innocence Staff. (2018). Report: Exonerations in 2017. Innocence Project.

The Justice Project. (2007). Electronic recording of custodial interrogations: A policy review. Washington, DC: Author.

Vrij, A. (1992). Credibility judgements of detectives: The impact of nonverbal behavior, social skills and physical characteristics on impression formation. The Journal of Social Psychology, 133(5), 601-610.

Vrij, A., Evans, H., Akehurst, L., \& Mann, S. (2004). Rapid judgements in assessing verbal and nonverbal cues: Their potential for deception researchers and lie detection. Applied Cognitive Psychology, 18(3), 283-296.

Vrij, A., Meissner, C. A., Fisher, R. P., Kassin, S. M., Morgan, C. A., \& Kleinman, S. M. (2017). Psychological perspectives on interrogation. Perspectives on Psychological Science, 12(6), 927-955.

Vrij, A., Meissner, C., \& Kassin, S. (2015). Problems in expert deception detection and the risk of false confessions: No proof to the contrary in Levine et al (2014). Psychology, Crime \& Law, 21(9).

Wagenaar, W. A., Van Koppen, P. J., \& Crombag, H. F. M. (1993). Anchored narratives. The psychology of criminal evidence. New York, NY: St. Martin's Press.

Warkentin, M., Sayeed, L., \& Hightower, R. (1997). Virtual teams versus face-to-face teams: An exploratory study of a web-based conference system. Decision Sciences, 28, 975-996.

Wells, G. L., Malpass, R. S., Lindsay, R. C. L., Fisher, R. P., Turtle, J. W., \& Fulero, S.M. (2000). From the lab to the police station. A successful application of eyewitness research. American Psychologist, 55, 581-598.

Zhou, L., Zhang, D., \& Sung, Y. (2013). The effects of group factors on deception detection performance. Small Group Research, 44(3), 272-297. 


\section{Author Biography}

Jillian R. Yarbrough is a clinical assistant and Virginia Engler Professor of Business Management at West Texas A\&M University. With more than 20 years of experience in distance learning and professional technology training, she has developed a unique teaching style in which academic discussion takes place within an entertaining and dynamic team forum. Yarbrough earned a BS degree from Texas Christian University and MS, MBA, and PhD degrees from Texas A\&M University. Her interests include social psychology and employees, strategic alignment between employees and organizational goals, creative compensation, corporate training and development, and human relations. 